\title{
Uma Proposta de um Serious Game no Auxílio do Aprendizado da Anatomia Humana
}

\author{
William B. Lemos ${ }^{1}$, Ivaldir H. Farias Junior ${ }^{1}$, Amadeu S. Campos Filho ${ }^{1,2}$ \\ ${ }^{1}$ Faculdade São Miguel, Recife, PE, Brasil \\ ${ }^{2}$ Núcleo de Telessaúde - Hospital das Clínicas - Universidade Federal de \\ Pernambuco (UFPE), Recife, PE, Brasil \\ \{baruchdelemos, ivaldirjr\}@gmail.com, amadeu.campos@nutes.ufpe.com\}
}

\begin{abstract}
The process of learning the discipline of human anatomy is complex, exhaustive and highly menorious. With this based on the theory of David Paul Ausubel (1918-2008) was created a Serious Game with the purpose of assisting in the process of learning the discipline. Using the Human-Centered Desing (HCD) method to create the Game and the descriptive method with qualitative and quantitative approaches to evaluate the same. We get results from Attrakdiff's usability test that prove that the game is desired and taskoriented. After analyzing the data we verified that the Game demonstrated efficiency as an educational technology bringing interactive and playful resources together with learning.
\end{abstract}

Resumo. O processo de aprendizado da disciplina de anatomia humana é complexo, exaustivo e altamente menóritico. Com isso baseado na teoria de David Paul Ausubel (1918-2008) foi criado um Serious Game com o objetivo de auxiliar no processo de aprendizado da disciplina. Foi utilizado o método Human-Centered Desing (HCD) para criar o Game e o método descritivo com abordagens qualitativas e quantitativas para avaliar o mesmo. Adquirimos com o teste de usabilidade do Attrakdiff resultados que provam que o Game é desejado e voltado para tarefas. Após a análise dos dados verificamos que o Game demonstrou eficiência como tecnologia educacional trazendo recursos lúdicos e interativos unidos ao aprendizado.

\section{Introdução}

Com o estudo da anatomia humana, o estudante da saúde passar a conhecer e entender melhor as formas e as estruturas do corpo humano, utilizando nomes, conhecidos como os termos anatômicos, para descrever o corpo humano e como eles estão relacionados com a doença, além de correlacionar as estruturas e entender como a terapia medicamentosa atua, possibilitando assim uma assistência de melhor qualidade. Segundo Souza (2001) "é de fácil compreensão que profissionais da saúde como fisioterapeutas e médicos, devam conhecer melhor possível a estrutura do corpo humano normal, esse conhecimento é fundamental para compreender as técnicas de avaliação do paciente, o mecanismo das patologias e seus tratamentos". 
Além disso, Vicente (1985) descreveu que a anatomia serve de base para vários outros conhecimentos na área de saúde como, por exemplo, semiologia, fisiologia, farmacologia, patologia, entre outras. Assim, é de grande importância que o processo de ensino e aprendizado da anatomia humana seja eficaz, permitindo aos futuros profissionais da saúde identificar e conhecer as diferentes formas e funções dos órgãos e estruturas do corpo na sua forma saudável para poder reconhecer e diferenciar as alterações patológicas.

Por outro lado, o aprendizado da anatomia humana é difícil, são vários os sistemas e inúmeros órgãos, estruturas e funções para estudar e conhecer, além da infinidade de nomes que necessitam serem decorados. Essa quantidade de conteúdo acaba afastando muitos discentes de uma base sólida em anatomia humana, impossibilitando uma futura atuação profissional de qualidade. Esse fato pode ser comprovado por Cardinot et al (2014) onde descreveu que o processo de ensino aprendizagem da anatomia é complexo, em virtude da grande quantidade de conceitos e estruturas a serem assimiladas pelos estudantes.

Para tornar um conteúdo complexo mais prazeroso e engajante de aprender, Lopes et al (2015) e Freitas e Adamatti (2016) relataram em seus estudos que o uso os jogos facilitou na obtenção de informação combinando o conteúdo com momentos lúdicos e interativos, aumentando a motivação do aprendizado e a fixação do conhecimento. Segundo Sá et al, (2007) "a utilização de jogos nas atividades de ensino possibilita oferecer ao aprendiz momentos lúdicos e interativos como etapas do processo de aprendizagem".

Diante desse Cenário é baseado na teoria da Aprendizagem Significativa proposta por Ausubel (1963), onde um novo conhecimento vai se relacionar de maneira não obrigada e não literal à estrutura cognitiva de aprendizagem foi criado um game educacional chamado de "esqueleto mania" que tem o objetivo de auxiliar no processo de ensino-aprendizado dos alunos de enfermagem na compreensão da anatomia humana em especial do sistema esquelético,

Assim, este artigo tem como objetivo descrever o processo de design do jogo, avaliar a usabilidade do mesmo e descrever a opinião e satisfação dos discentes de enfermagem na utilização do jogo como suporte tecnológico para o processo ensinoaprendizado da anatomia humana.

\section{Materiais e métodos}

A pesquisa foi do tipo descritiva onde pretende descrever os fatos e fenômenos observados e analisados. Para realizar esse estudo foi utilizado primeiramente o método de engenharia de software cujo objetivo foi desenvolver o jogo "esqueleto mania". O desenvolvimento também foi baseado nas práticas de Human-Centered Design [HCD, 2017] que é um processo composto por um conjunto de técnicas divididas em três fases (Escutar, Criar e Implementar) utilizadas para criar novas soluções e modos de interação. Na fase de escutar foram realizadas as técnicas de análise bibliográfica, levantamento dos competidores e entrevista com usuários para serem definidos os requisitos necessários para a criação do game. Na fase de criação foram utilizadas os métodos de análise de contexto, personas e cenários com especialistas para geração de protótipos interativos utilizando as técnicas de paper prototyping, wireframe $\mathrm{e}$ prototipagem de alta fidelidade. Na fase de implementar, o serious game esqueleto 
mania foi construído com a versão gratuita do Game Engine Construct 2 enquanto as imagens para jogos 2D foram construídos como a ferramenta Gimp. As fases de criação e implementação foram realizadas em parceria com alunos do curso de desenvolvimento de jogos digitais

O estudo também foi baseado na abordagem qualitativa e quantitativa onde teve caráter exploratório e também estatístico com o método de análise de usabilidade e percepção do usuário. A variável qualitativa usada para capturar a percepção de usuários no estudo foi feita de forma observacional de cunho empírico onde ocorreu a procura de dados relevantes e convenientes obtidos através da experiência. As variáveis quantitativas utilizadas para analisar a usabilidade foram a efetividade, tempo de uso e percepção do usuário através do questionário Attrakdiff [Gerhardt \& Silveira, 2009].

O AttrakDiff tem a capacidade de medir a percepção do usuário sobre o objeto pretendido e segundo Valentim (2015, p.4) "permite avaliar a atratividade através dos diferentes aspectos de uma aplicação". O questionário foi dividido em três dimensões: i. a Qualidade Pragmática (QP) referente à qualidade da aplicação e os objetivos desejados alcançado pelo usuário; ii. a Qualidade Hedônica que é dividida em Estímulo $(\mathrm{QH}-\mathrm{S})$ que aponta até onde o objeto preenche as necessidades do usuário e promover um interesse, motivação, etc e Qualidade Hedônica de Identidade (QE-I) que indicar até que ponto ocorreu uma identificação da necessidade do usuário com a aplicação; iii. Atratividade (ATT) que indica o valor geral da aplicação, baseado na percepção da qualidade. Além disso, o AttrakDiff é composto por vinte e oito pares de palavras agrupadas nas dimensões onde cada par de palavras foram colocados nos extremos da escala com diferencial semântico de sete pontos ( -3 a 3 , sendo 0 como ponto neutro).

\subsection{Cenário}

A avaliação de usabilidade e satisfação do jogo foi realizada com a participação voluntária de 20 discentes de enfermagem de duas instituições de ensino, uma de nível superior com uma amostra de 10 discentes e outra de nível médio com uma amostra de 10 alunos, todos da região do metropolitana do Recife, no mês de junho de 2017. O único critério exclusão foi não ter sido aprovado na disciplina de anatomia humana. $\mathrm{O}$ teste aconteceu em vários momentos durante o período descrito e foi dividido em três etapas, Na primeira o aluno usou por tempo livre. Dessa forma, foi possível verificar o tempo de imersão do jogador. Além disso foi proposto ao aluno realizar duas tarefas: reconhecer alguns ossos do jogo e passar no mínimo de duas fases do jogo. Na segunda etapa, os discentes preencheram o teste de satisfação padronizado da Attrakdiff cujo objetivo foi identificar problemas de usabilidade, analisar a experiência do usuário e determinar a satisfação do participante com o produto. Na terceira e última etapa foi pedido para o aluno relatar oralmente ou escrever sua opinião sobre o jogo, suas críticas, modificações, sugestões que ele faria e tudo mais que ele julgar ser relevante. Durante o teste de usabilidade foram feitas as anotações necessárias através das observações e de gravações das opiniões dos usuários para depois serem analisadas.

\section{Resultados e discussão}

\subsection{O Jogo}

$\mathrm{Na}$ fase de escutar do método de Design centrado no usuário foi possível levantar todos os requisitos necessários para o design e implementação de todas as Interfaces e 
VI Congresso Brasileiro de Informática na Educação (CBIE 2017)

Anais do XXVIII Simpósio Brasileiro de Informática na Educação (SBIE 2017)

funcionalidade do jogo "esqueleto mania", Dentre os requisitos levantados e analisados, houve a necessidade de adotar uma metodologia mais divertida, engajada, estimulante e menos entediante sem abandonar as teorias de aprendizagem como também o conteúdo a ser estudado.

Nesse contexto, desenvolvemos a solução de um quebra-cabeça onde o usuário teria que além de conhecer o conteúdo do sistema esquelético fosse também capaz de identificar algum elemento ósseo e encaixá-lo no local correto através de recursos lúdicos. As interfaces gráficas do serius game simulavam um ambiente de quebracabeça onde teria de um lado um quadro com os elementos do sistema esquelético (ossos) e do outro a forma de um esqueleto. O usuário teria que mover cada osso para seu local de origem correto no esqueleto onde em seguida aparecerá o nome do mesmo, sinalizando que o usuário acertou o local que a estrutura deve ficar. $\mathrm{O}$ jogo é composto inicialmente um total de dez fases, cada uma com os ossos de diferentes regiões do corpo humano como: cintura escapular, membros superiores, cintura pélvica, etc., A Figura 01 é uma das fases do jogo onde ilustra os ossos do crânio.

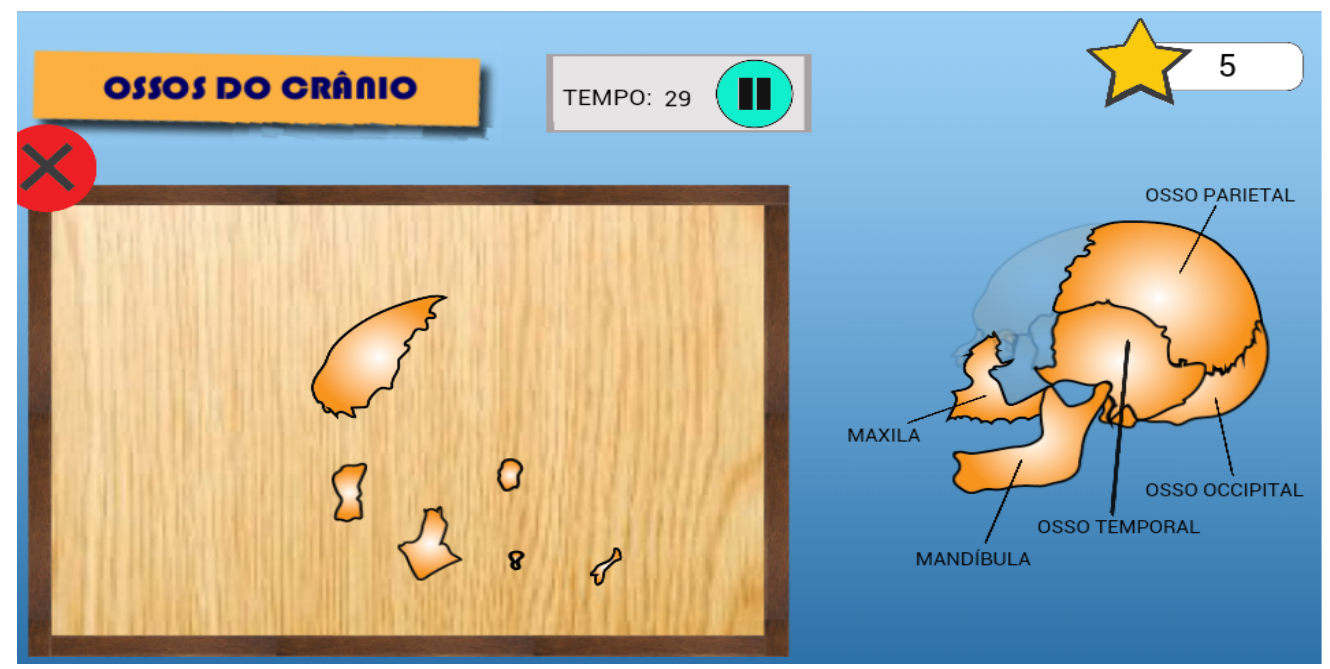

Figura 1 - Um dos estágios do Seriuos Game "Esqueleto Mania"

\subsection{Avaliação de Usabilidade}

\subsubsection{Efetividade}

O cálculo da efetividade foi medido pela variável de quantidade de acertos ocorridos na primeira tarefa que era verificar as imagens dos ossos e informar se elas aparentavam assemelhar as estruturas ósseas. Do total de 20 alunos, 11 alunos (55\%) informaram que as estruturas do jogo não apresentaram grande diferença da estrutura real, 4 alunos $(20 \%)$ disseram que as imagens apresentam uma semelhança suficiente para diferenciar uma da outra, porém não chegavam a parecer estruturas reais e 5 alunos (25\%) informaram que as imagens não aparentavam uma estrutura óssea o suficiente para estudantes da saúde. Em relação a quantidade de fases concluídas, do total de alunos, 19 concluíram pelo menos uma fase, apenas uma pessoa não conseguiu passar de nenhuma fase.

\subsubsection{Tempo de utilização}


VI Congresso Brasileiro de Informática na Educação (CBIE 2017)

Anais do XXVIII Simpósio Brasileiro de Informática na Educação (SBIE 2017)

O tempo que os discentes possuíam para usar o jogo esqueleto mania foi livre, assim podemos avaliar o quanto o jogo os envolvia. O tempo de imersão médio dos alunos foi de 14,55 minutos, sendo o tempo médio dos discentes da graduação de enfermagem de 16,3 minutos e os discentes do curso técnico de enfermagem de 10,8 minutos conforme a Figura 2.

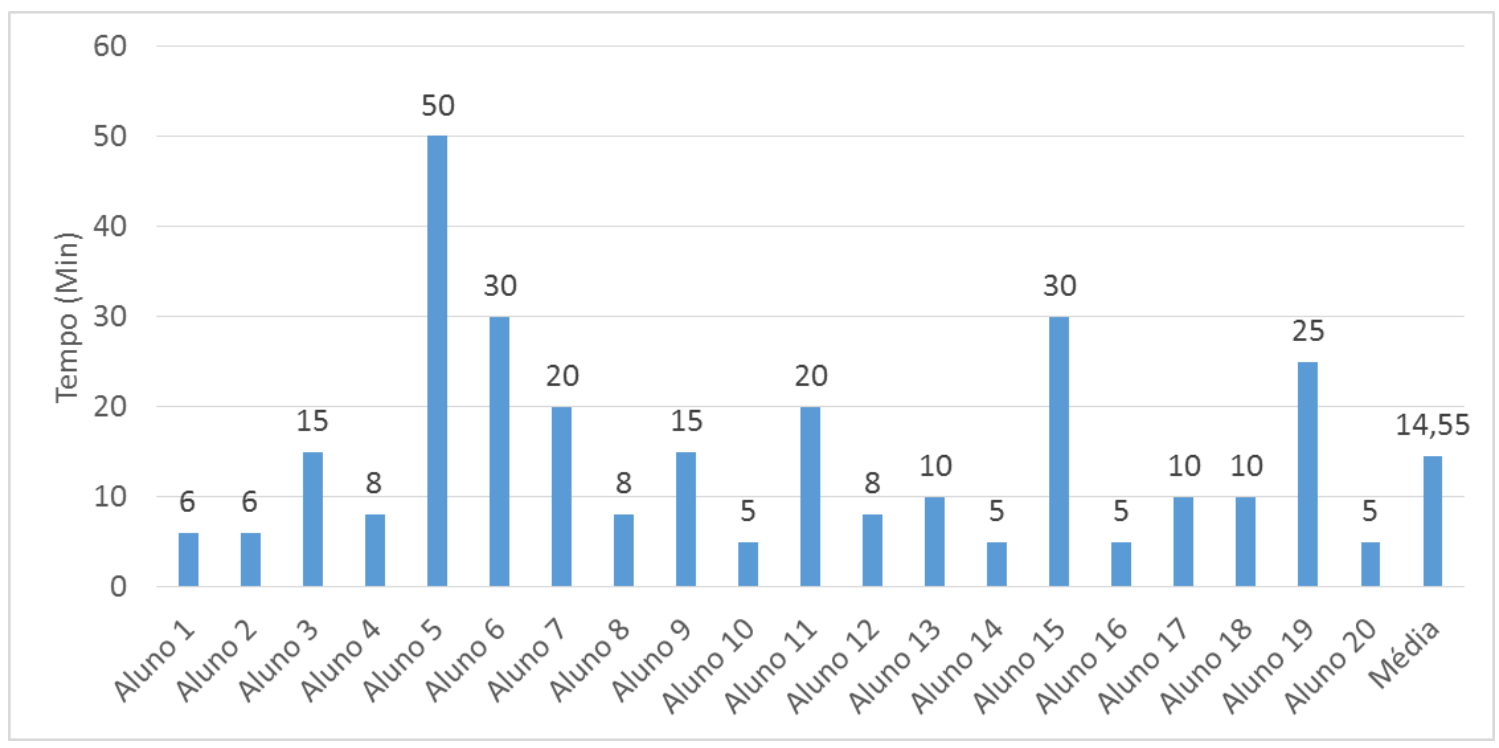

Figura 2. Tempo de imersão do jogador

De acordo com a figura 2, podemos observar que os alunos concluíram as fases com tempo curto e sem grande dificuldade. O tempo que o próprio jogo disponibilizava para concluir os estágios variava entre 50 segundos a 1 minuto e meio, impossibilitando os usuários de apreciarem o jogo mais detalhadamente e conhecerem melhor o conteúdo a ser estudado. Em contrapartida foi feita a cronometragem do tempo que os discentes passaram jogando para poder verificar se o jogo estava sendo motivador. Mais de $90 \%$ dos alunos demonstraram um engajamento em concluir as fases e quase sempre era auscultada a frase "eu me lembro desse osso ou dessa estrutura". Segundo Savi (2010, p.5) "bons jogos levam o jogador a ter uma experiência de profundo envolvimento no jogo, que geralmente provoca um desvio de foco do mundo real para o mundo do jogo".

Essa experiência de envolvimento com o jogo faz com que o conteúdo a ser estudado seja aprendido mais facilmente devido ao direcionamento da atenção do aluno. Segundo Ladewig (2000, p.2) a "atenção exerce uma função muito importante na capacidade de retenção de informações relevantes, pois é através dela, associada aos processos de controle, que guardamos informações na memória de longa duração". Assim podemos avaliar que o serious game teve uma grande capacidade de reter a atenção dos estudantes, apesar de não ter sido o esperado, pois a especificação do Serious game era estabelecer um tempo para concluir as fases, ao acabar esse tempo o usuário não passava de fase e tinha de começar tudo novamente.

\subsubsection{Satisfação}

O questionário attrakdiff foi respondido por 20 alunos que participaram do teste de usabilidade do jogo esqueleto mania e os resultados das 3 dimensões podem ser visualizados nas figuras 3 e 4 . 
VI Congresso Brasileiro de Informática na Educação (CBIE 2017)

Anais do XXVIII Simpósio Brasileiro de Informática na Educação (SBIE 2017)

Diagrama de valores médios

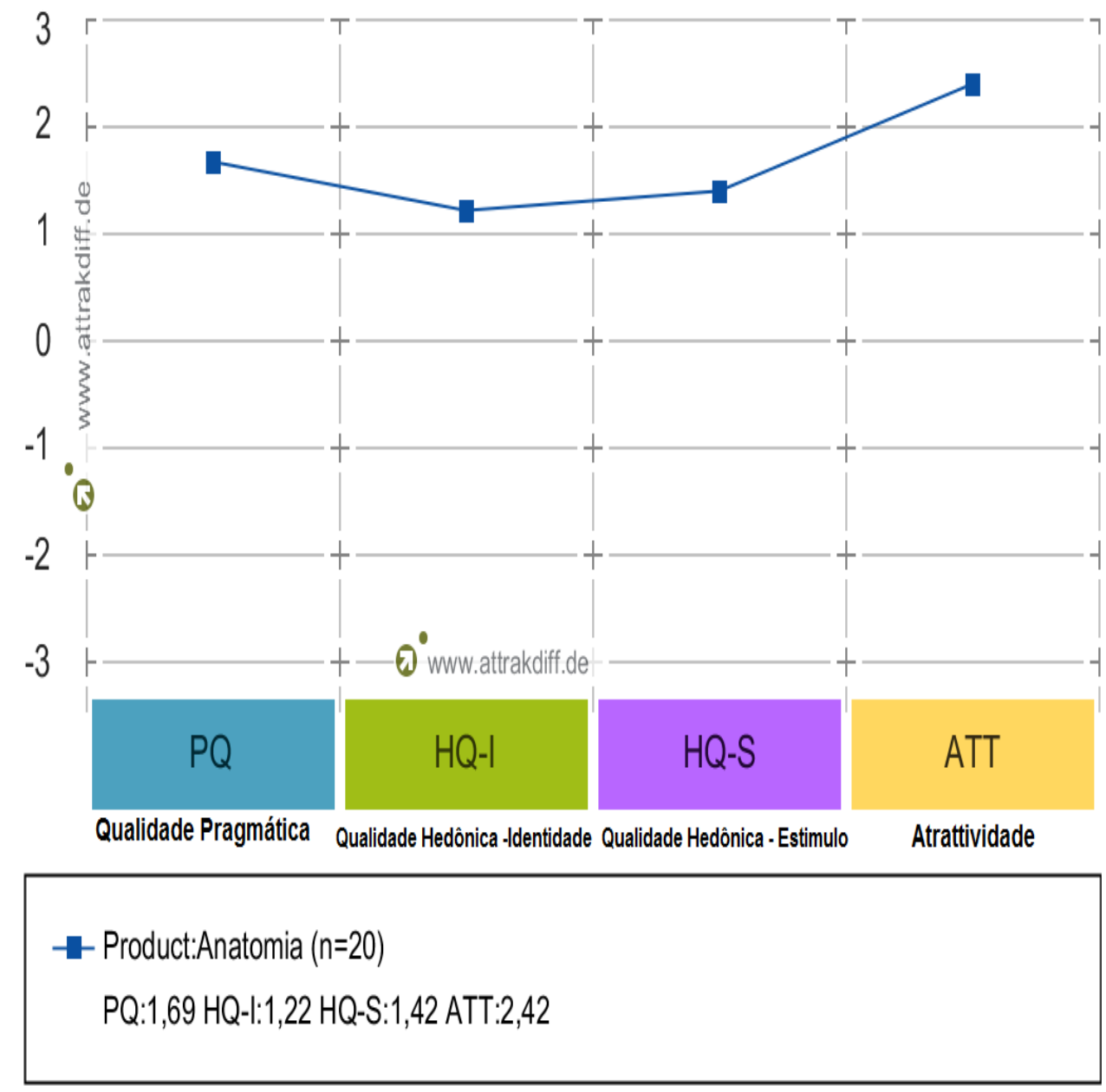

Figura 3. Os valores adquiridos no AttrakDiff (traduzido pelos autores). 


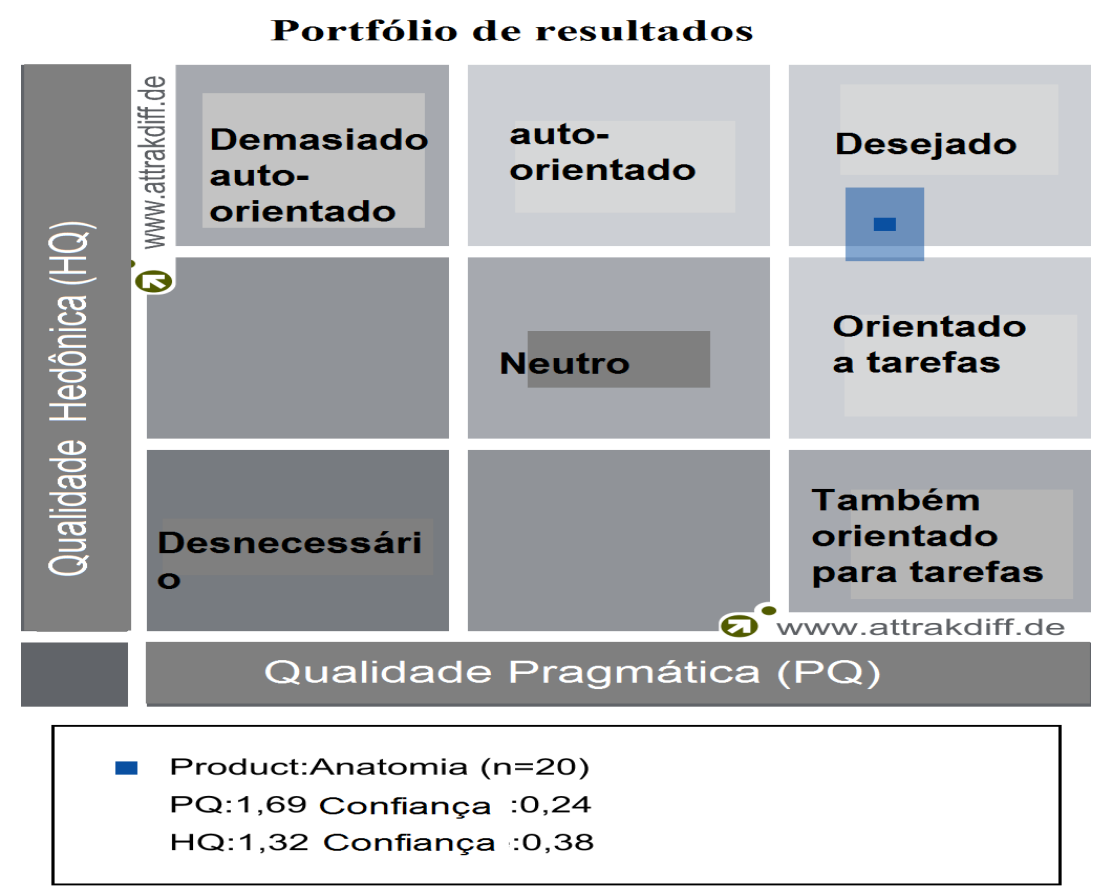

Figura4. Resultado geral do AttrakDiff (traduzido pelos autores)

De acordo com a figura 4 percebemos que a Qualidade Pragmática (PQ) a qual indica a satisfação do usuário em atingir seus objetivos com a aplicação, indicou uma pontuação de 1,69 onde o que mais se sobressaiu no Serious game foi sua praticidade, simplicidade, estruturação e gerenciamento. Porém foi perceptível alguns pontos a serem trabalhados futuramente como previsibilidade e a clareza excessiva. A Qualidade Hedônica de Identidade (HQ-I) que indica o nível de identificação do usuário com o aplicativo teve pontuação de 1,22 que foi o menor valor médio entre todos. Esse fato ocorreu possivelmente pelo baixo nível de dificuldade do serious game destinado a alunos de uma idade mais avançada e que buscam conhecimentos mais profundos, contudo a elegância, aproximação com pessoas e a apresentação, satisfizeram os alunos, mas a falta de conectividade e dificuldade atrapalhou uma maior identificação dos alunos.

Na Qualidade Hedônica de Estímulo (HQ-S), a qual avalia se o aplicativo é original, interessante e estimulante obteve pontuação de 1,42 onde os principais itens que se sobressaíram foram a engenhosidade e a criatividade, demonstrando que o jogo inovou e trouxe uma proposta diferente para estudar a anatomia humana. A Atratividade (ATT), que diz o quanto o serious game foi atrativo para o usuário teve uma pontuação de 2,42 aproximando ao valor máximo. Por último, a agradabilidade é o fator motivador e atraente do jogo foi o que mais se destacou.

De acordo com AttrakDiff(2017) e com a análise dos resultados na figura 3, pode-se considerar que o jogo é desejável nas duas dimensões pragmáticas e hedônicas. Elas são claramente destacadas nesse quadrante, indicando que o produto auxilia, desperta o interesse e estimula os usuários. O intervalo de confiança da qualidade pragmática $(0,24)$ é menor do que o da qualidade hedônica $(0,38)$, embora esteja somente localizado em um único quadrante. Isso pode ser atribuído às classificações 
VI Congresso Brasileiro de Informática na Educação (CBIE 2017)

Anais do XXVIII Simpósio Brasileiro de Informática na Educação (SBIE 2017)

diferentes dadas pelos usuários, indicando também que há espaços ainda para melhoria do produto em termos de sua qualidade pragmática.

Para permitir um melhor detalhamento da avaliação dos usuários, foi contabilizado cada item individualmente, a média da pontuação de cada uma das vinte e oito questões de cada aluno. A Figura 5 mostra a média do total de pontos que cada questão obteve somando-se as respostas dos 20 alunos que participaram da avaliação.

Descrisão dos pares de palavras
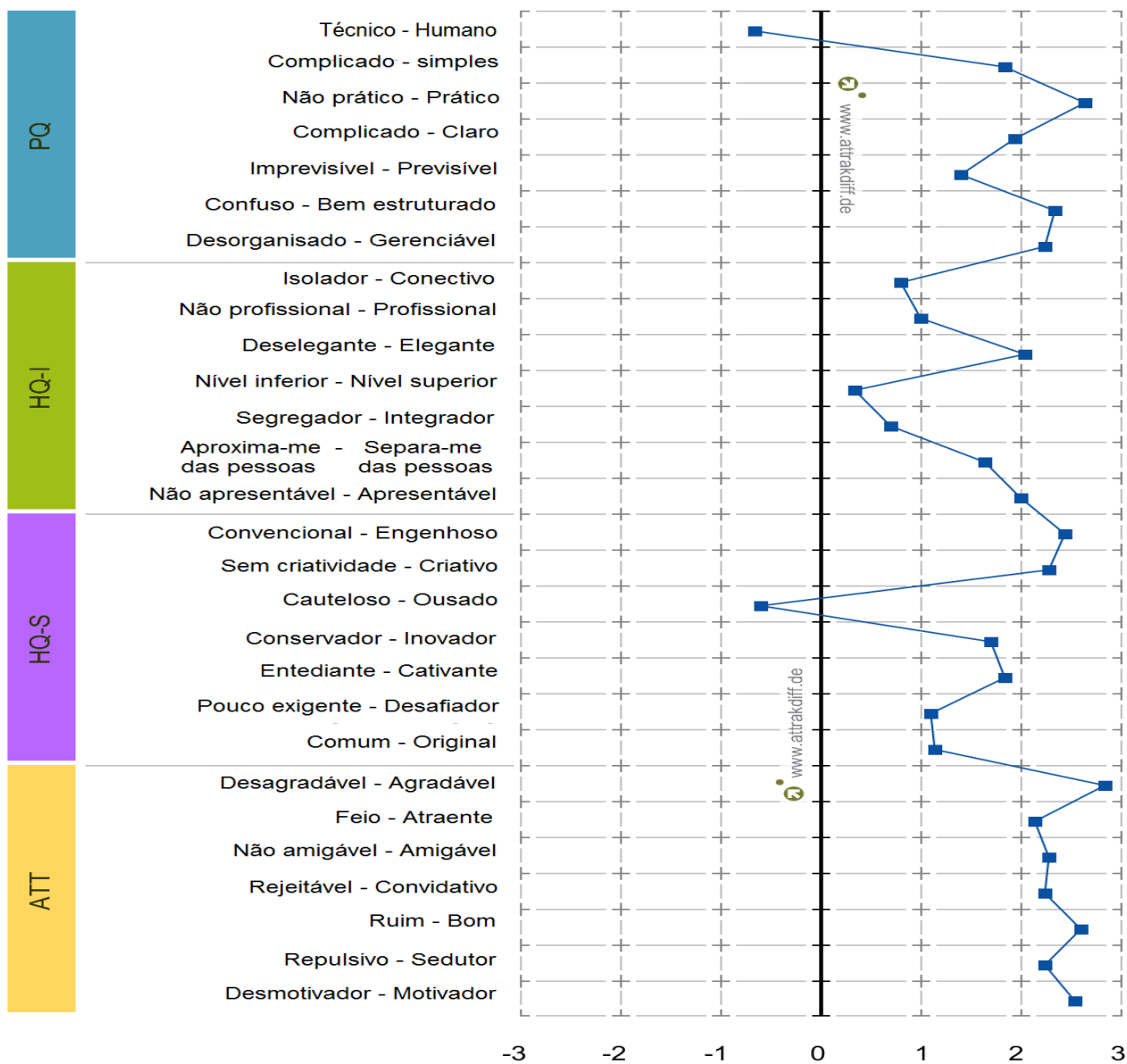

- Product:Anatomia $(\mathrm{n}=20)$

Figura5. Itens do questionário baseado em uma escala com diferencial semântico (traduzido pelos autores)

De acordo com a figura 5, a maioria dos itens teve uma pontuação positiva com exceção dos itens, Técnico - Humano $(-0,70)$ e o Cauteloso - Ousado $(-0,70)$ que deram valores abaixo de zero (negativo). $\mathrm{O}$ fato do jogo ter sido caracterizado como técnico e cauteloso ocorreu em virtude do desenvolvimento do game está relacionada com as limitações impostas pela Engine na versão gratuita Construct2. Em contrapartida, o item desagradável - agradável teve a maior pontuação positiva em virtude do jogo atrair e motivar os alunos a usá-lo e consequentemente a aprender o conteúdo pretendido, porém a principal melhoria a ser feita é direcionar o serious game a necessidade 
VI Congresso Brasileiro de Informática na Educação (CBIE 2017)

Anais do XXVIII Simpósio Brasileiro de Informática na Educação (SBIE 2017)

específica do estudante de saúde de nível técnico ou superior, possibilitando assim que haja uma maior identificação do usuário com o Game.

Com a análise qualitativa dos dados coletados foi possível verificar assuntos comuns que foram citados com maior frequência pelos alunos e também os pontos positivos e negativos do Serious Game "Esqueleto Mania" no auxílio do aprendizado da anatomia humana, entre eles:

- Aparência do jogo: 11 alunos (55\%) relataram que o jogo apresenta gráficos de boa qualidade e agradáveis, onde o design é atraente.

- Adicionar quizzes: 10 alunos (50\%) relataram que a utilização de perguntas e respostas é algo necessário para o jogo.

- Multiplayer: 05 alunos (25\%) sugeriram que jogar com outras pessoas melhoraria o processo de aprendizado

- Gameplayer: 19 (95\%) alunos informaram que o jogo deveria ser mais desafiador, pois a baixa dificuldade em completar as fases acarretaria em falta de estimulação.

- Performance do jogo: 04 alunos (20\%) relataram baixa performance do serious game em montar as estruturas. Esse fato pode ter ocorrido devido ao tamanho de algumas imagens

- Qualidade das Imagens: 11 alunos (55\%) disseram que as imagens seriam adequadas para o ensino médio e que para os estudantes de graduações e cursos técnico o ideal seria imagens das estruturas reais em 3 dimensões (3D).

Além dessas observações, os dados coletados na fase de imersão do jogo demonstraram que as imagens criadas dos ossos com a intenção cativar o usuário, não foram totalmente aceitas pelos alunos. Isso ocorreu devido ao fato de que as imagens não foram projetadas para serem idênticas as estruturas originais, mas sim serem apenas ilustrações não realistas, apenas comparativas. Outro fato que corroborou para isso foi que os usuários do teste eram alunos que já tiveram contato com estruturas reais e desejavam ver as mesmas.

\section{Conclusões}

Levando-se em conta o que foi observado percebemos que o serious game "Esqueleto Mania" demonstrou eficiência como tecnologia educacional destinada a auxiliar o aprendizado da anatomia humana trazendo recursos lúdicos, interativos e facilitando a obtenção dos conhecimentos anatômicos de forma simples e rápida, aumentando a motivação do aprendizado e a fixação do conhecimento. Com a avaliação de usabilidade e a experiência do usuário pode-se comprovar o nível de usabilidade das interfaces e satisfação do usuário referente a proposta do Serious Game.

Também verificamos que o jogo é muito estimulante e inovador provocando um interesse e motivação para a sua utilização no aprendizado da anatomia humana, onde a atratividade do Game foi validada. Contudo notamos que a identificação dos estudantes da graduação de enfermagem com o serious game foi a inferior do esperado. Isso se deu devido ao baixo grau de dificuldade no gameplay do jogo e a falta de mecanismos em avaliar os conhecimentos adquiridos pelos alunos, onde os mesmos sugeriram de forma geral a adição de um Quiz. 
Além disso não foi possível abordar ainda todos os sistemas encontrados na anatomia humana devido algumas restrições da ferramenta de construção do jogo, porém existem outras ferramentas, como o Blender, Unreal 4 Engine, Cocos $2 D-X$, Love, etc, que podem disponibilizar gratuitamente todos os recursos para $\mathrm{o}$ desenvolvimento do jogo com mais características. Uma nova versão do jogo está sendo desenvolvida com novas idéias através da incorporação de imagens de estruturas reais para tornar o jogo mais atraente e eficiente no processo de aprendizagem. Por fim concluímos que o jogo desenvolvido e avaliado demonstrou um leque de possibilidade para o desenvolvimento de jogos que auxiliar o aprendizado do estudante de saúde.

\section{Referências}

AttrakDiff. (2017). Disponível em: < http://attrakdiff.de/>. Acesso em 10 jun. 2017

AUSUBEL, D. (1963) The Psychology of Meaningful Verbal Learning. New York: Grune \& Stratton.

Cardinot, T.M., Oliveira, J.R., Júnior, O.V.P., Machado, M.A., Macedo, M.A., Aragão, A.H.B.M. (2014). Importância da Disciplina de Anatomia Humana para os Discentes de Educação Física e Fisioterapia da Abeu Centro Universitário de Belford Roxo/Rj. Coleção Pesquisa Em Educação Física, Várzea Paulista/Sp, V. 13, N. 1, P.95-102.

Freitas, V., \& Adamatti, D. (2016). Educa Direito: A Serious Game for the Teaching of Labor Law. Brazilian Journal of Computers in Education, 24(03), 1. doi:http://dx.doi.org/10.5753/rbie.2016.24.3.1

Gerhardt, T.E., Silveira, D.T. (2009). Métodos de pesquisa. Porto Alegre: Editora da UFRGS

HCD METHODS. Disponível em: <http://www.hcdconnect.org/methods>. Acesso em: 17 jul. 2017.

Ladewig, I. (2000). A Importância da Atenção na Aprendizagem de Habilidades Motoras. Rev. Paul. Educ. Fís., São Paulo, Supl.3, P.62-71

Lopes, R. A.; Toda, A. M.; Brancher, J. D. (2015) Um estudo preliminar sobre elementos extrínsecos e intrínsecos do processo de Gamification. Revista Brasileira de Informática na Educação, Volume 23, $\mathrm{N}^{\circ} 03$.

Savi, R., Wangenheim, C. G., Ulbricht, V., Vanzin, T.(2010). Proposta de um Modelo de Avaliação de Jogos Educacionais. CINTED-UFRGS V. 8 No 3, dezembro

Sá, E.J.V; Teixeira, J.S.F; Fernandes, C.T (2007) Design de Atividades de Aprendizagem que Usam Jogos como Princípio para Cooperação. In: Anais Do Xviii Simpósio Brasileiro De Informática Na Educação (Sbie), São Paulo - Sp, Brasil

Souza, R. R. (2001). Anatomia Humana. São Paulo: Manole

Vicente De Castro,Sebastião.(1985). Anatomia Fundamental. 3 Ed. São Paulo: Makron Books

Valentim; N. M. C., Silva, W.A. F., Conte, T. (2015). Avaliando a Experiência do Usuário e a Usabilidade de um Aplicativo Web Móvel: Um Relato de Experiência. XVIII Congresso Ibero-Americano em Engenharia de Software, Volume: 1 